\title{
Spore test parameters matter: Mesophilic and thermophilic spore counts detected in raw milk and dairy powders differ significantly by test method
}

\author{
D. J. Kent, K. Chauhan, K. J. Boor, M. Wiedmann, and N. H. Martin ${ }^{1}$ \\ Milk Quality Improvement Program, Department of Food Science, Cornell University, Ithaca, NY 14853
}

\begin{abstract}
United States dairy industry exports have steadily risen in importance over the last $10 \mathrm{yr}$, with dairy powders playing a particularly critical role. Currently, approximately half of US-produced nonfat dry milk and skim milk powder is exported. Reaching new and expanding existing export markets relies in part on the control of endospore-forming bacteria in dairy powders. This study reports baseline mesophilic and thermophilic spore counts and spore populations from 55 raw material samples (primarily raw milk) and 33 dairy powder samples from dairy powder processors across the United States. Samples were evaluated using various spore testing methodologies and included initial heat treatments of $(1) 80^{\circ} \mathrm{C}$ for $12 \mathrm{~min}$; (2) $100^{\circ} \mathrm{C}$ for $30 \mathrm{~min}$; and $(3) 106^{\circ} \mathrm{C}$ for $30 \mathrm{~min}$. Results indicate that significant differences in both the level and population of spores were found for both raw milk and dairy powders with the various testing methods. Additionally, on average, spore counts were not found to increase significantly from the beginning to the end of dairy powder processing, most likely related to the absence of biofilm formation by processing plant-associated sporeformers (e.g., Anoxybacillus sp.) in the facilities sampled. Finally, in agreement with other studies, Bacillus licheniformis was found to be the most prevalent sporeformer in both raw materials and dairy powders, highlighting the importance of this organism in developing strategies for control and reduction of spore counts in dairy powders. Overall, this study emphasizes the need for standardization of spore enumeration methodologies in the dairy powder industry.
\end{abstract}

Key words: dairy powder, raw milk, spore test method, Bacillus licheniformis

Received August 19, 2015.

Accepted March 4, 2016.

${ }^{1}$ Corresponding author: nhw6@cornell.edu

\section{INTRODUCTION}

Aerobic endospore-forming bacteria of the Bacillaceae family have been recognized as major contributors to dairy product quality issues over the past 2 decades (Ralyea et al., 1998; Huck et al., 2007b; Ranieri and Boor, 2009). In spore form, these organisms are capable of surviving environmental stresses including low $\mathrm{pH}$, high temperature, exposure to sanitizers, high pressure, and others (Logan and Devos, 2009). These qualities, combined with sporeformers' ubiquitous presence in natural environments (Carlin, 2011), have led to interest in controlling their entry into the dairy product continuum, on the farm (Vissers et al., 2006; Masiello et al., 2014; Miller et al., 2015a), in the transportation chain (Huck et al., 2008), and in the processing environment (Flint et al., 1997; Scott et al., 2007). In recent years, the presence of mesophilic and thermophilic spores in dairy powders has gained increasing attention, as specifications for these microorganisms in powders have become progressively more stringent (Watterson et al., 2014).

Mesophilic spores have been shown to be the most prevalent sporeformer found in bulk tank raw milk (Miller et al., 2015b). Organisms such as Bacillus licheniformis and Bacillus pumilus predominate in raw bulk tank milk (Ivy et al., 2012; Miller et al., 2015b) and appear to originate primarily from the dairy farm environment (te Giffel et al., 2002; Huck et al., 2008). In contrast, thermophilic spores are more prevalent in dairy powders (Watterson et al., 2014). Studies across the globe have consistently identified Bacillus licheniformis, Anoxybacillus sp., and Geobacillus sp. as the 3 primary sporeformers present in dairy powders (Ronimus et al., 2003; Rückert et al., 2004; Scott et al., 2007; Yuan et al., 2012). While Anoxybacillus sp. and Geobacillus sp. are considered obligate thermophiles (i.e., optimum growth temperatures of 50 to $62^{\circ} \mathrm{C}$ and 55 to $65^{\circ} \mathrm{C}$, respectively; Pikuta, 2009; Logan et al., 2009) and are generally associated with the dairy processing environment (Flint et al., 1997; Scott et al., 2007), Ba- 
cillus licheniformis is capable of growing at mesophilic temperatures as well as thermophilic temperatures and is found throughout the dairy production and processing continuum (Ivy et al., 2012).

Strategies to reduce the prevalence and levels of spores in dairy powders include reducing their entry into raw milk (Masiello et al., 2014; Miller et al., 2015a) and controlling their presence and growth in processing environments (Flint et al., 1997; Scott et al., 2007). The success of these approaches is evaluated based on results of spore testing in the final product (i.e., reducing spore counts). Unfortunately, this seemingly straightforward process is more complicated than it would seem due to the lack of standardization in spore testing methodologies. Although a host of testing methodologies have been devised to enumerate spores in dairy products (Murphy et al., 1999; Hill, 2004; Scheldeman et al., 2005; ISO-IDF, 2009), there is little in the way of standardization when it comes to spore tests. Initial heat treatments to eliminate vegetative cells and select for spores range from $80^{\circ} \mathrm{C}$ to $125^{\circ} \mathrm{C}$ for 10 to $30 \mathrm{~min}$; combined with incubation temperatures to select for mesophilic (i.e., $30-32^{\circ} \mathrm{C}$ ) or thermophilic (i.e., $55^{\circ} \mathrm{C}$ ) spores and various plating media, this leads to the potential for hundreds of unique spore test combinations. This makes national and global benchmarking and comparison nearly impossible. Additionally, although some spore tests are designed to target specific groups of sporeforming bacteria, in general, little is known regarding the effects of different spore treatments on the population of spores that will be detected.

To this end, the objective of this study was to utilize various commonly used spore enumeration methodologies to compare baseline mesophilic and thermophilic spore levels and populations in raw milk and dairy powders sourced from across the United States, and to test the specific hypotheses that (1) increasing spore counts throughout a processing run would indicate the presence of in-plant associated sporeforming bacteria (i.e., Anoxybacillus); and (2) spore testing parameters affect both the level and types of spores recovered from dairy powders. Results of this study will enable the US and global dairy industries to compare and reference spore levels in both raw milk and dairy powders, and define standard methods for enumeration of spores in dairy powder products, thereby allowing for targeted efforts to reduce spore levels in these products.

\section{MATERIALS AND METHODS}

\section{Dairy Powder Processing Plants}

Eleven dairy powder processing plants located either in the east (plants A, B, E, F, I, and K) or the west regions $(\mathrm{C}, \mathrm{D}, \mathrm{G}, \mathrm{H}, \mathrm{J})$ of the United States participated in the survey study. Each of the 11 dairy plants manufactures one of the following finished powder products: whey protein concentrate (WPC; plant A), nonfat dry milk (NDM; plants B, C, D, E, F, and K), skim milk powder (plants $\mathrm{G}$ and $\mathrm{H}$ ), and whole milk powder (plants I and J). All plants made milk powders from raw material (RM), primarily raw milk, except for plants A and E, which used cheese whey and condensed milk, respectively. The length of the production runs for each of the 11 dairy plants varied between 6.5 and $44 \mathrm{~h}$.

\section{Sample Collection}

In total, 5 RM (representing RM used during the entire processing run) and $3 \mathrm{FP}$ samples [representing the beginning (within $1 \mathrm{~h}$ of processing start-up), middle (within $\pm 1 \mathrm{~h}$ of projected mid-point of processing run), and end (within $1 \mathrm{~h}$ of shut-down) of the processing run] were collected by plant personnel once from each of the 11 dairy plants over the 10-mo sampling period (July 2013 to April 2014). Detailed sampling instructions and checklists for sample collection, storage, and shipping were provided to plant personnel. Fluid samples and powder samples were aseptically collected in 10-oz. (296-mL) Capitol Plastics locking vials and 24-oz. (710-mL) Whirl-Pak bags, respectively, and were held at or below $6^{\circ} \mathrm{C}$ until tested within $24 \mathrm{~h}$ of arrival at the Milk Quality Improvement Program (MQIP) laboratory (Cornell University, Ithaca, NY).

\section{Spore Treatment and Enumeration}

Aerobic spores were enumerated using methods described previously (Watterson et al., 2014). Briefly, 11 $\mathrm{g}$ of each finished powder sample was rehydrated in $99 \mathrm{~mL}$ of PBS with magnesium chloride under aseptic conditions. Five spore tests were performed on 100 $\mathrm{mL}$ each of the $\mathrm{RM}$ and rehydrated finished powder samples, each test comprising a heat treatment to inactivate vegetative bacterial cells followed by spreadplating in duplicate on brain heart infusion (BHI) agar (Difco, BD, Sparks, MD) and incubation to recover viable spores. The methods used were (1) spore pasteurized mesophilic spore count (SP-MSC; $80^{\circ} \mathrm{C}$ for $12 \mathrm{~min}$ followed by incubation at $32^{\circ} \mathrm{C}$ for $48 \mathrm{~h}$ ); (2) spore pasteurized thermophilic spore count (SP-TSC; $80^{\circ} \mathrm{C}$ for 12 min followed by incubation at $55^{\circ} \mathrm{C}$ for 48 h); (3) highly heat resistant mesophilic spore count (HHR-MSC; $100^{\circ} \mathrm{C}$ for $30 \mathrm{~min}$ followed by incubation at $32^{\circ} \mathrm{C}$ for $48 \mathrm{~h}$ ); (4) highly heat resistant thermophilic spore count (HHR-TSC; $100^{\circ} \mathrm{C}$ for $30 \mathrm{~min}$ followed by incubation at $55^{\circ} \mathrm{C}$ for $48 \mathrm{~h}$ ); and (5) specially thermo- 
resistant spore enumeration (STSE; $106^{\circ} \mathrm{C}$ for $30 \mathrm{~min}$ followed by incubation at $55^{\circ} \mathrm{C}$ for $48 \mathrm{~h}$ ). Condensed milk and WPC samples that thickened during heat treatment were diluted 2:1 in PBS following heat treatment to enable plating.

An enrichment step was performed on all heat-treated samples to enable detection of spores present in low levels. Thirty-milliliter aliquots from each spore test were incubated for $48 \mathrm{~h}$ alongside the plates. For those samples where the final count after direct plating was below the detection limit (i.e., no colonies present on BHI plate), a $10-\mu \mathrm{L}$ aliquot of the enriched sample was streaked on BHI and then incubated under corresponding (i.e., $32^{\circ} \mathrm{C}$ or $55^{\circ} \mathrm{C}$ ) conditions for $24 \mathrm{~h}$.

Individual colonies were selected from samples treated with different spore tests (SP-MSC, SP-TSC, HHR-MSC, HHR-TSC, and STSE) following direct plating or enrichment, selecting one for each unique colony morphology. Isolates were streaked for purity on BHI and frozen for further characterization in $15 \%$ glycerol (wt $/ \mathrm{vol})$ at $-80^{\circ} \mathrm{C}$.

\section{rpoB Gene Sequencing for Identification of Bacterial Spores}

Isolates were characterized as previously reported (Huck et al., 2007a). Briefly, cultures from frozen stocks were streaked onto BHI agar and incubated at either $32^{\circ} \mathrm{C}$ or $55^{\circ} \mathrm{C}$ for 24 to $48 \mathrm{~h}$. A single colony was picked with a sterile toothpick and resuspended in $100 \mu \mathrm{L}$ of distilled water followed by heating in a microwave for 3 min at maximum power. The PCR amplification was performed using a touchdown PCR method with primer pairs rpoB-V3F (5'-AARYTNGGHCCDGARGAAAT-3') and rpoB-V3R (5'-TGNARYTTRTCRTCRACCATGTG-3'), amplifying a 740-nucleotide rpo $B$ gene fragment. The PCR reagents and thermocycling conditions used were as described by Durak et al. (2006). The products confirmed by $1.5 \%$ agarose gel electrophoresis were then purified using an ExoSAP method (Dugan et al., 2002), submitted for a bidirectional sequencing using the same primer pair at the Cornell Biotechnology Resource Center (Cornell University), and analyzed as described previously (Ivy et al., 2012). Each isolate was assigned an rpoB allelic type (AT) as described previously (Huck et al., 2007b; Ivy et al., 2012). Each rpoB AT represents a unique sequence within a specific 632-nucleotide region of the amplified gene fragment. For isolates that could not be identified by their rpoB AT sequence, a 700-nucleotide segment of the $16 \mathrm{~S}$ gene was sequenced for species identification as previously described (Huck et al., 2007b) and compared with $16 \mathrm{~S}$ sequences from all Bacillales-type strains obtained from the Ribosomal Database Project (Cole et al., 2014). Separate multiple alignments for the rpo $B$ and $16 \mathrm{~S}$ sequences were generated and trimmed using MUSCLE (Edgar, 2004) and AliView (Larsson, 2014), respectively. All sequences were edited using Sequencher software 5.0 (Gene Codes Corp., Ann Arbor, MI). For each alignment, a maximum-likelihood phylogenetic tree was generated using the rapid maximumlikelihood algorithm RAxML (Stamatakis, 2006) with rapid bootstrapping (100 bootstrap replicates). These trees were used to provide genus and species identification as described previously (Ivy et al., 2012).

\section{Statistical Analysis}

All analyses were performed in the R Statistical Programming Environment (R Core Team, 2015). Spore counts were modeled using a multilevel Poisson mixedeffect regression with observation-level random effects with the "lme4" package. Sample material (i.e., raw material and powder) and spore test method were entered as fixed effects, whereas sample and plant were entered as random effects, with samples nested within plants. Post hoc least-squares means tests were performed with the "Ismeans" package, using the Tukey method for multiple testing correction. Spore population similarities were examined with the analysis of similarity (ANOSIM) method, using the "vegan" package.

\section{RESULTS}

\section{Spore Counts in Raw Milk and Dairy Powders and Spore Test Parameters}

Overall, of the 55 raw material samples (45 raw milk, 5 cheese whey, and 5 condensed milk) collected from 11 dairy powder processors across the US, 100, 98, 80,84 , and $29 \%$ were positive either on direct plating or after enrichment for SPMSC, SPTSC, HHRMSC, HHRTSC, and STSE tests, respectively (Supplemental Table S1; http://dx.doi.org/10.3168/jds.2015-10283). Log mean spore counts in raw materials intended for powder production were $1.60,1.20,0.90,1.80$, and 0.20 $\log \mathrm{cfu} / \mathrm{mL}$ for SPMSC, SPTSC, HHRMSC, HHRTSC, and STSE, respectively (Figure 1). Additionally, of the 33 finished powder samples tested, 100, 100, 82, 100, and $85 \%$ were positive for SPMSC, SPTSC, HHRMSC, HHRTSC, and STSE, respectively (Supplemental Table S1). Log mean spore counts in powder samples were $2.30,3.40,1.10,3.20$, and $2.50 \mathrm{log} \mathrm{cfu} / \mathrm{g}$ for SPMSC, SPTSC, HHRMSC, HHRTSC, and STSE, respectively (Figure 1). 


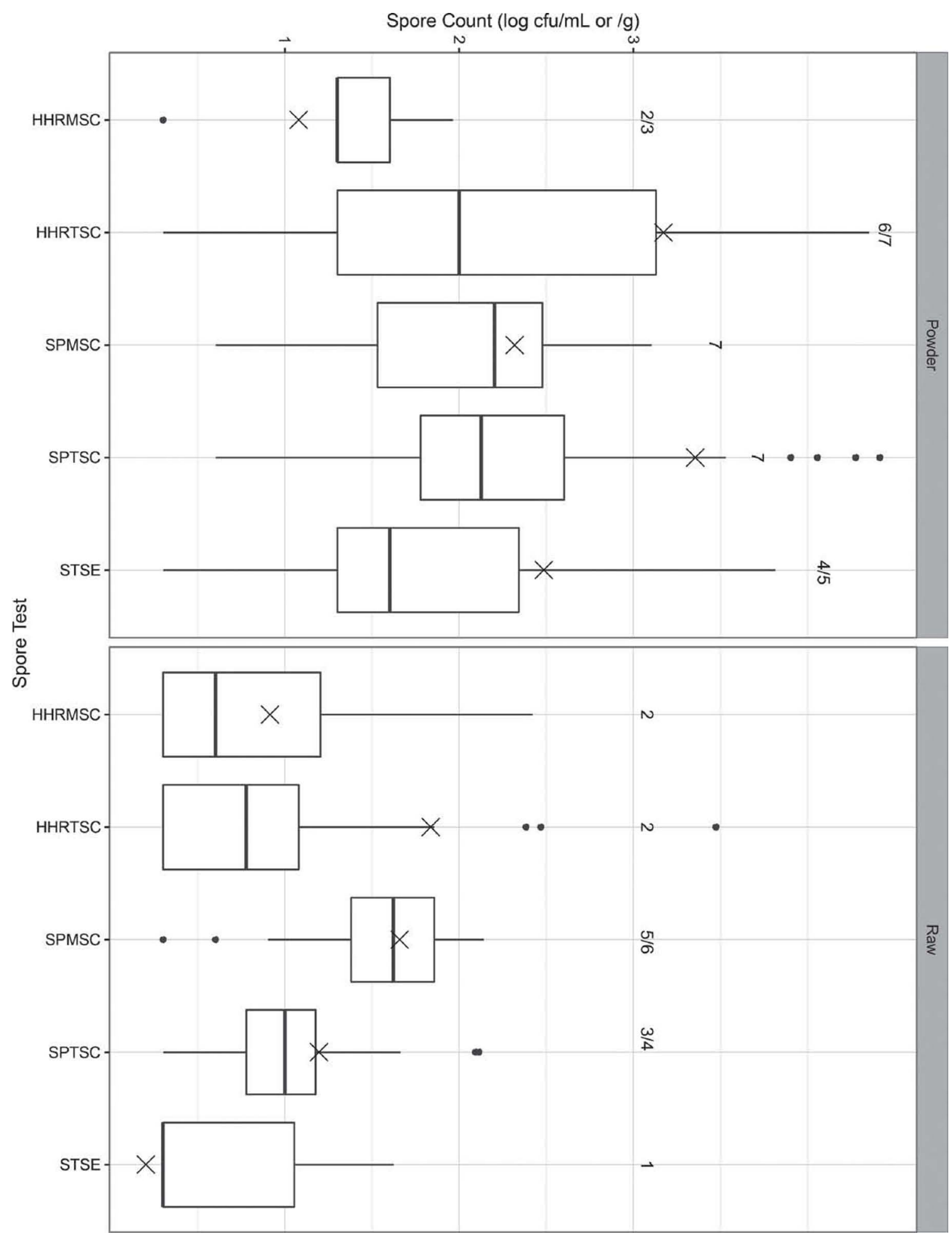

Figure 1. Boxplots representing the distribution of spore counts from 5 spore count methods: SPMSC $=$ spore pasteurized mesophilic spore count; SPTSC $=$ spore pasteurized thermophilic spore count; HHRMSC $=$ highly heat resistant mesophilic spore count; HHRTSC $=$ highly heat resistant thermophilic spore count; and STSE = specially thermoresistant spore enumeration from 33 dairy powder samples and 55 raw material samples (45 raw milk, 5 cheese whey, and 5 condensed milk) sourced from 11 US dairy powder processors. Dark horizontal lines within the boxplot represent median spore count values; $\times$ represents the log mean spore count for each respective test. Ends of each box represent the first and third quartiles, whiskers represent minimum and maximum values (excluding outliers), and black circles represent outliers. Different numbers above the boxplots represent significant $(P<0.05)$ differences in spore counts. 
Of the 5 spore count methods used in this study, STSE resulted in significantly lower spore counts in RM than SPMSC, SPTSC, HHRMSC, and HHRTSC $(P<0.0001, P<0.0001, P=0.0024$, and $P<0.0001$, respectively); HHRMSC and HHRTSC, although not significantly different from each other $(P=0.5157)$, were significantly lower than SPMSC (both comparisons $P<0.0001)$ and SPTSC $(P<0.0001$ and $=0.0010$, respectively). Finally, SPMSC in RM were significantly higher than SPTSC $(P=0.0027)$.

Results showed that in dairy powders, HHRMSC was significantly lower than SPMSC, SPTSC, HHRTSC, and STSE $(P<0.0001,<0.0001,<0.0001$ and $=$ 0.0009 , respectively). In addition, STSE was significantly lower than SPMSC, SPTSC, and HHRTSC $(P$ $<0.0001$ for all 3 comparisons), whereas HHRTSC, SPMSC, and SPTSC were not significantly different from each other $(P>0.2$ for all comparisons). Correlations between different spore count methods (including raw and powder samples) ranged from 0.0886 for log STSE versus log HHRMSC to 0.843 for $\log$ SPTSC versus log HHRTSC (Figure 2).

\section{Mean Thermophilic Spore Counts During Processing Runs}

No significant increase was found in dairy powder spore counts (all methods combined) throughout a processing run $(P=0.39)$, despite a trend for increasing counts from beginning to middle and end (2.19, 3.00 , and $3.15 \log$ mean cfu/g, respectively; Figure 3). The comparison of mesophilic spore count between the beginning and the end of processing showed a slight decrease of $0.15 \mathrm{log} \mathrm{cfu} / \mathrm{g}$ in the HHRMSC method and a slight increase of $0.30 \mathrm{log} \mathrm{cfu} / \mathrm{g}$ in the SPMSC method. Conversely, all of the thermophilic spore counts tended to increase from beginning to the end of processing, with increases of $1.22,0.90$, and 1.09 for the SPTSC, HHRTSC, and STSE methods, respectively (Figure 3). However, despite the trend for increasing counts in the thermophilic methods, none represented a significant increase $(P=0.19)$.

\section{Bacillus licheniformis in Raw Milk and Dairy Powders}

A total of 326 isolates were collected from 33 dairy powder samples and 55 raw material samples from 11 US dairy powder processors. Of those, $126(39 \%)$ isolates were collected from powder, and the remaining 200 isolates were collected from RM $(61 \%)$. Among the 126 isolates collected from powder samples, 39 (31\%), $44(35 \%), 6(5 \%), 16(13 \%)$, and $21(16 \%)$ were iso- lated from SPMSC, SPTSC, HHRMSC, HHRTSC, and STSE, respectively (Figure 4). Similarly, of the 200 isolates collected from raw samples, 85 (43\%), 59 (30\%), $12(6 \%), 33(16 \%)$, and $11(5 \%)$ were isolated from SPMSC, SPTSC, HHRMSC, HHRTSC, and STSE, respectively (Figure 4).

Overall, a total of 11 genera and 25 unique species represented by 96 unique rpo $B$ AT were collected in this study (Supplemental Table S2; http://dx.doi. org $/ 10.3168 /$ jds.2015-10283). Of the 326 isolates, $B a-$ cillus licheniformis, represented by rpoB AT 1, 6, 9, $31,169,173,215,549$, and 560, accounted for 51\% (n $=166$ ) of all isolates (Figure 4; Supplemental Table 2). Additionally, Bacillus licheniformis (all AT) was isolated from all spore count methods, all plants, all time points (beginning, middle, and end of processing), and both raw and powder products, making it the most ubiquitous organism isolated in this study. Bacillus licheniformis AT1 alone accounted for just over 30\% of all isolates $(\mathrm{n}=100)$ and was isolated from all spore count methods, all plants, all time points, and both raw and powder products (Figure 4; Supplemental Table 2). In total, the genus Bacillus accounted for 263 isolates, or $81 \%$, of total isolates collected.

Following Bacillus, the second most commonly isolated genus was Geobacillus $(9 \%, \mathrm{n}=30)$. In contrast to Bacillus, Geobacillus was only isolated from 6 of the 11 plants, with 20 of the $30(67 \%)$ isolates coming from plant A (Supplemental Table S2; http://dx.doi. org/10.3168/jds.2015-10283). Also in contrast to $B a-$ cillus, Geobacillus was only isolated from thermophilic tests (SPTSC, HHRTSC, and STSE) and was isolated from both raw and powder products and all processing time points (Figure 4; Supplemental Table 2). The remaining isolates were characterized as Aeribacillus ( $\mathrm{n}=$ 9), Paenibacillus $(\mathrm{n}=8)$, Brevibacillus $(\mathrm{n}=3)$, Lysinibacillus $(\mathrm{n}=3)$, Oceanobacillus $(\mathrm{n}=3)$, Psychrobacillus $(\mathrm{n}=2)$, Sporosarcina $(\mathrm{n}=2)$, Ureibacillus $(\mathrm{n}=2)$, and Anoxybacillus ( $\mathrm{n}=1$; Supplemental Table 2).

Analysis of similarity (ANOSIM) was used to determine spore population similarities, based on rpoB AT, between samples of various types. Results showed that spore populations differed significantly between plant $(P=0.001)$, spore count method (i.e., the combination of heat treatment and incubation temperature; $P=$ $0.04)$, and heat treatment $(P=0.015)$. No significant difference was found between spore populations for product (raw and powder; $P=0.381$ ), processing time point (beginning, middle, or end; $P=0.617$ ), or incubation temperature $\left(32^{\circ} \mathrm{C}\right.$ or $\left.55^{\circ} \mathrm{C} ; P=0.817\right)$. Figure 4 illustrates the reduction in AT diversity as increasing heat treatment was used for spore count methods. For example, dairy powder samples analyzed using the 


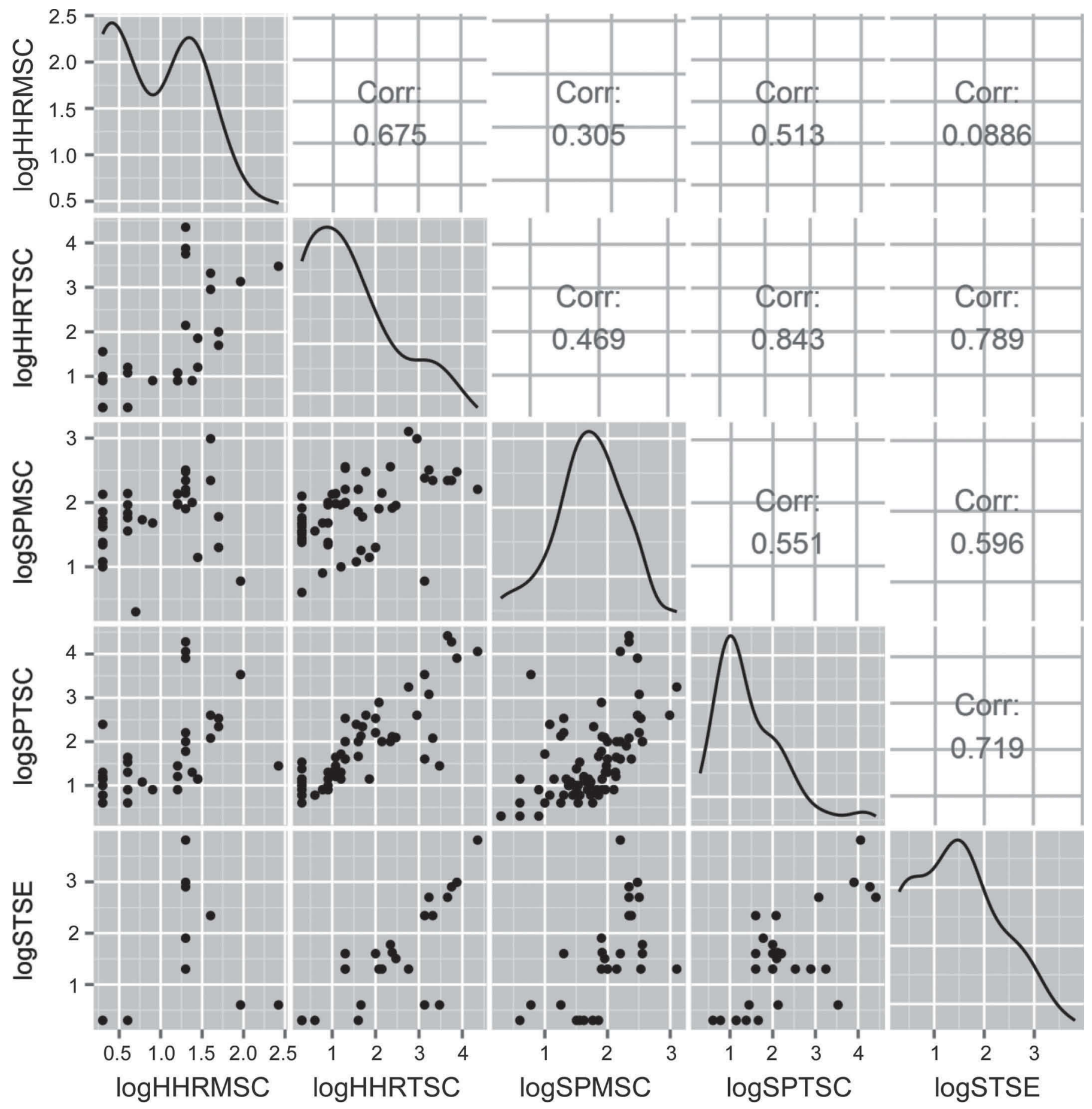

Figure 2. Comparison of various spore count methods: SPMSC $=$ spore pasteurized mesophilic spore count; SPTSC $=$ spore pasteurized thermophilic spore count; HHRMSC = highly heat resistant mesophilic spore count; HHRTSC = highly heat resistant thermophilic spore count; and STSE = specially thermoresistant spore enumeration. Lower triangle contains scatterplots of log-transformed spore counts between different spore tests, and only samples with nonzero counts for both tests are included in each plot. Upper triangle contains the correlations (Corr.) of the log-transformed spore counts between different spore tests. Diagonal contains kernel density estimates for the probability distribution of each test.

SPTSC test resulted in 10 unique $\mathrm{AT}$, whereas the same powder analyzed using the HHRTSC and STSE tests resulted in 7 and 5 unique AT, respectively (Fig- ure 4). Further, only 3 unique AT were identified in the powder treated with the HHRMSC method, whereas the SPMSC method resulted in 29 unique AT, the larg- 
est number of unique AT per test found in powder in this study (Figure 4).

\section{DISCUSSION}

\section{Benchmarking Mesophilic and Thermophilic Spore Counts in Dairy Powders}

This study reports baseline spore counts using various methods for raw milk (and other raw materials) and dairy powders across the United States. Figure 1 shows the distribution of spore counts by product (raw or powder) and spore count method, providing a benchmarking tool for the dairy powder industry. Previous studies have reported that spore counts in dairy powders (based on various spore count methods) ranged from below the detection limit to $>10^{4} \mathrm{cfu} / \mathrm{g}$ (Muir et al., 1986; Rückert et al., 2004; Yuan et al., 2012; Watterson et al., 2014; Buehner et al., 2014). Log mean spore counts of US dairy powders in our study ranged

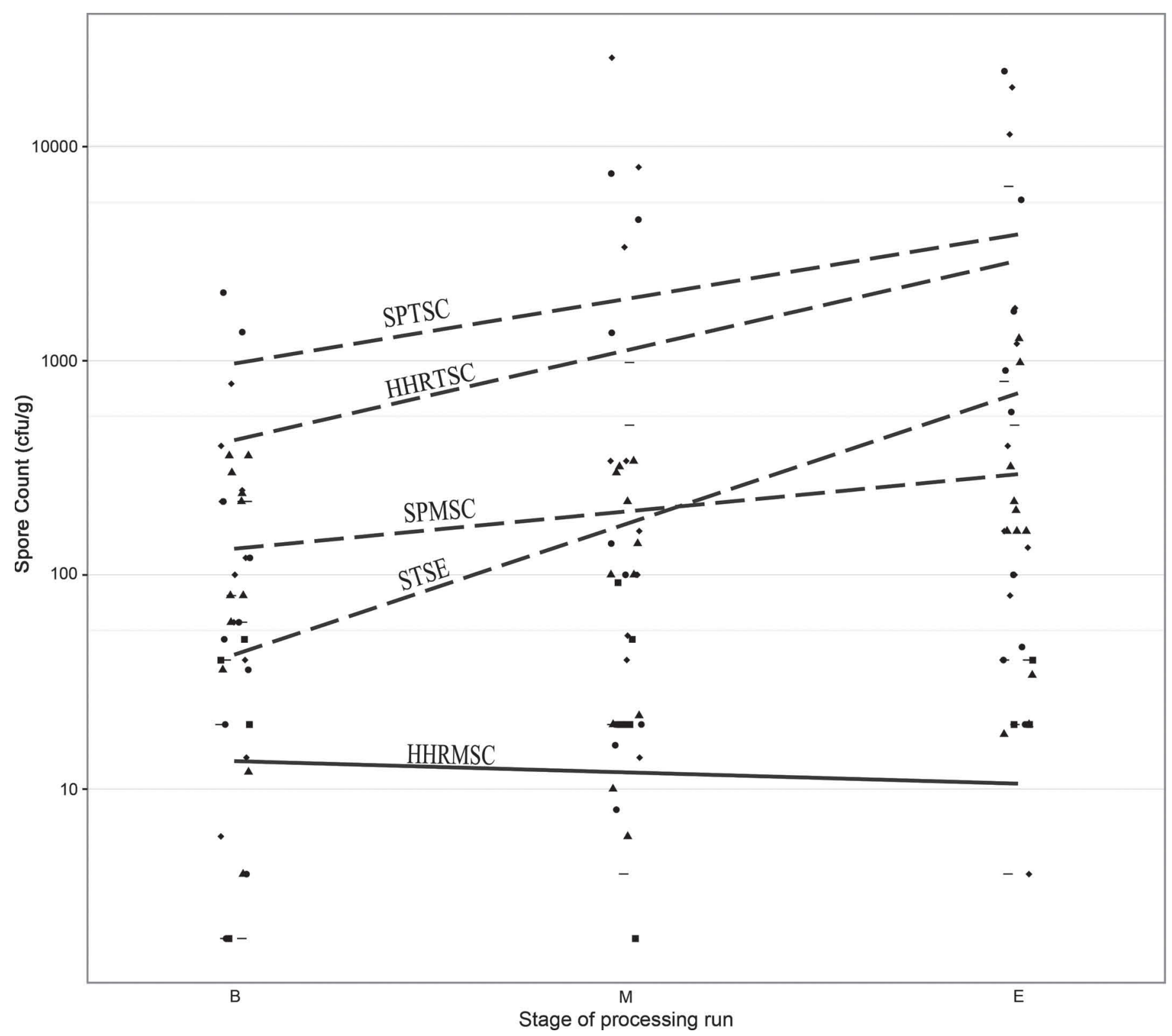

Figure 3. Spore counts at beginning (B), middle (M), and end (E) stages of a dairy powder processing run. Trend lines represent Poisson regression for each individual spore test: spore pasteurized thermophilic spore count (SPTSC, $\bullet$ ); highly heat resistant thermophilic spore count (HHRTSC, ๑); spore pasteurized mesophilic spore count (SPMSC, $\mathbf{\Delta}$ ); specially thermoresistant spore enumeration (STSE, -); highly heat resistant mesophilic spore count (HHRMSC, $\mathbf{\square})$. 


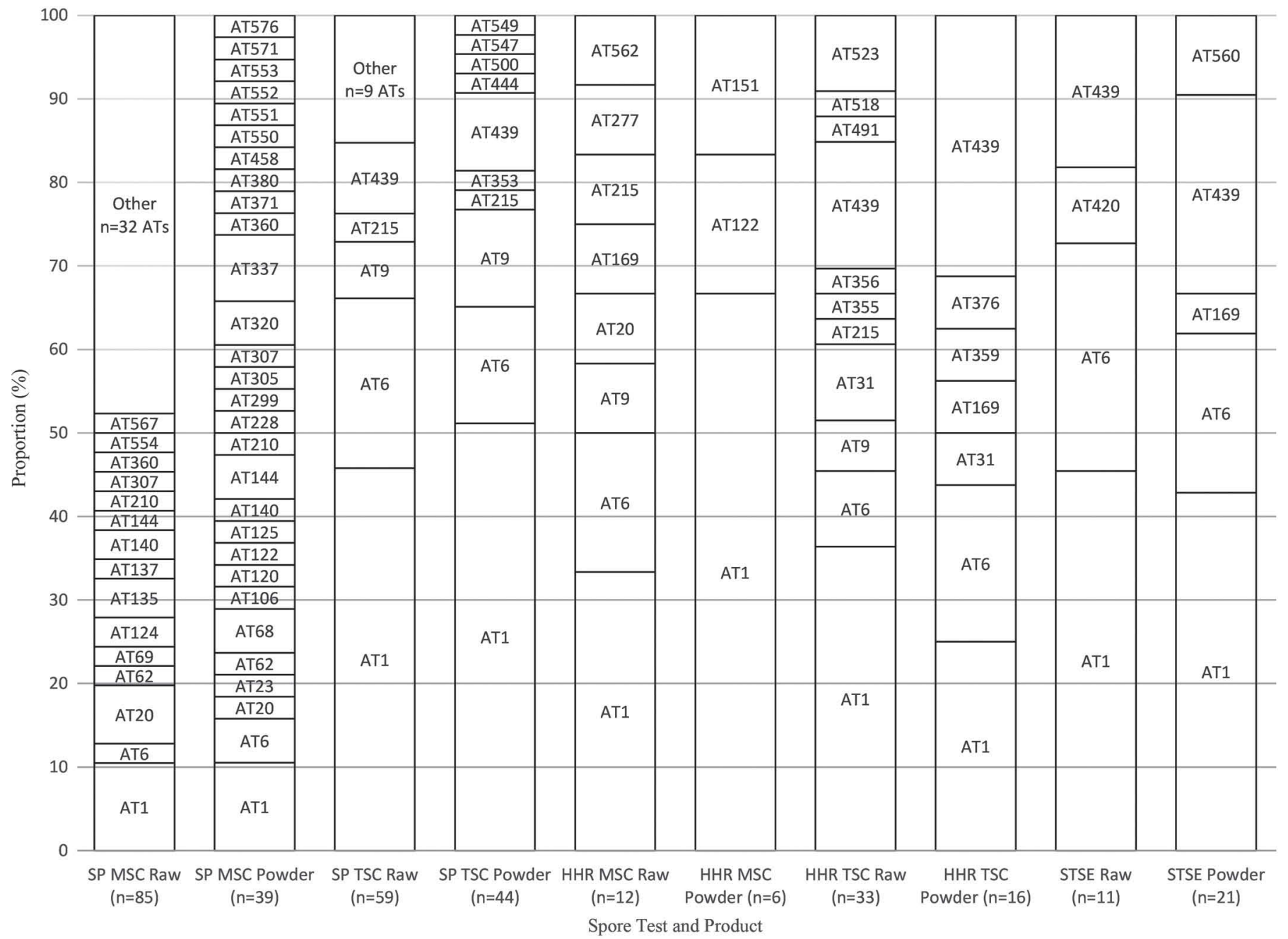

Figure 4. Spore population diversity as defined by $r p o B$ allelic type (AT) for each test and product from 11 US dairy powder processors. Tests: SPMSC = spore pasteurized mesophilic spore count; SPTSC = spore pasteurized thermophilic spore count; HHRMSC $=$ highly heat resistant mesophilic spore count; HHRTSC = highly heat resistant thermophilic spore count; and STSE = specially thermoresistant spore enumeration. $\mathrm{n}=$ number of spore isolates collected from each corresponding product and test; "other" represents AT found at $<2 \%$ prevalence in the corresponding product and method.

from 1.10 for STSE to $3.40 \mathrm{log} \mathrm{cfu} / \mathrm{g}$ for SPMSC, well within and even at the low end of the range of previously reported spore counts.

Baseline spore counts in RM and dairy powders in this study were found to differ significantly by spore test method (Figure 1). Various methods for enumerating aerobic spores in dairy products have been previously described. The standard method, outlined in Standard Methods for the Examination of Dairy Products (Frank and Yousef, 2004), includes a heat treatment for 12 min at $80^{\circ} \mathrm{C}$ to eliminate vegetative cells followed by incubation at $32^{\circ} \mathrm{C}$ for $48 \mathrm{~h}$ to enumerate mesophilic spores or $7^{\circ} \mathrm{C}$ for $10 \mathrm{~d}$ to enumerate psychrotolerant spores. Examples of other methods include those selecting for highly heat resistant spores (heat treatment of $100^{\circ} \mathrm{C}$ for $30 \mathrm{~min}$; Murphy et al., 1999; Scheldeman et al., 2005) and those selecting for specific heat-resistant microorganisms (heat treatment of $106^{\circ} \mathrm{C}$ for $30 \mathrm{~min}$; Hill, 2004; ISO-IDF, 2009). All of these methods use a similar strategy - heat treatment for a specific timetemperature combination to eliminate vegetative cells, plating on a spore recovery medium (i.e., BHI agar, tryptic soy agar, plate count milk agar), a factor not studied here but that may contribute to variability in spore counts, and incubation at various temperatures to select for groups (i.e., psychrotolerant, mesophilic, and thermophilic) of sporeforming microorganisms. It is not surprising, given the variation among these methods, and indeed the intention for some methods to select for different groups of sporeforming microorganisms, that we detected significant differences in the levels and populations of sporeforming bacteria 
detected among the spore tests used in this study. Watterson et al. (2014) found a similar pattern in samples from 4 northeastern US dairy powder processing facilities. Those authors found that only $7.3 \%$ of samples were positive on direct plating for mesophilic spores after $100^{\circ} \mathrm{C} / 30$ min spore treatment compared with an $80^{\circ} \mathrm{C} / 12$ min, which resulted in over $30 \%$ of samples being positive for mesophilic spores. Additionally, those authors found that nearly 2 times more samples were positive for thermophilic spores when subjected to an $80^{\circ} \mathrm{C} / 12$ min spore treatment than when treated at $100^{\circ} \mathrm{C} / 30$ min (Watterson et al., 2014). Buehner et al. (2014) also found that mesophilic spore counts were significantly lower than thermophilic spore counts in dairy powders from the Midwest United States with a heat treatment of $80^{\circ} \mathrm{C}$ for $12 \mathrm{~min}$ used for both mesophilic and thermophilic spore counts. These significant differences among spore count and spore populations among test methods also explain why a relatively low correlation was found when results from these methods are compared (Figure 2), leading to the conclusion that overall, these tests do not convey the same information and therefore are not interchangeable.

In general, it is easy to see how many combinations might be derived from the 4 parameters that constitute a spore test (i.e., heat treatment temperature, heat treatment time, medium, and incubation temperature), leading to hundreds of possible methods. This lack of standardization in spore testing methodologies leads to complications and confusion when comparing, benchmarking, and interpreting spore levels in powder from the United States and abroad. Our study highlights the importance of establishing standard methods, using scientifically validated data, for the examination of spore levels in dairy powders. Although results from this study do not shed light on which spore test parameters are ideal for use in the dairy powder industry, they do demonstrate that small changes in these parameters can make significant differences in outcomes. For this reason, our recommendation would be for the dairy powder industry to pursue the adoption of more than one standardized method (i.e., SPMSC, HHRTSC, and STSE) to capture the diversity of sporeforming bacteria commonly found in dairy powders. Different standardized spore test methods could also be used to evaluate powders that are used in different applications (i.e., infant formula versus cheese making).

\section{Bacillus licheniformis Is a Hurdle to Reduction of Spore Counts in Dairy Powders}

Bacillus licheniformis was, by far, the most frequently isolated sporeforming microorganism from both raw materials and dairy powder in this study. It was identified in all products, tests, and time points and was isolated from all 11 plants enrolled in this study. Previous work has identified Bacillus licheniformis as one of the principal spore contaminants in dairy powders across the globe (Ronimus et al., 2003; Rückert et al., 2004; Reginensi et al., 2011; Miller et al., 2015b). A survey of commercial milk powders in China revealed that Bacillus licheniformis accounted for $27.8 \%$ of the total isolates (Yuan et al., 2012), lower than the prevalence found in our study (50.9\%). Buehner et al. (2014) also found Bacillus licheniformis to be the most prevalent sporeformer, accounting for $63 \%$ of isolates, in NDM powders from the Midwestern United States. In addition to widespread prevalence in dairy powders around the world, Bacillus licheniformis has been described as one of the most prevalent sporeforming bacteria present in raw milk (Crielly et al., 1994; te Giffel et al., 2002; Ivy et al., 2012; Miller et al., 2015b). Further, Bacillus licheniformis is widespread in the dairy farm environment (te Giffel et al., 2002; Huck et al., 2008). The ubiquitous nature of Bacillus licheniformis from the dairy farm environment, in raw milk, and in dairy powders requires that particular attention be paid to preventing the entry of this organism into raw milk as well as eliminating it from dairy powder processing environments to reduce dairy powder spore counts.

Second only to Bacillus, Geobacillus accounted for just over $9 \%$ of the total sporeformers characterized from raw materials and powder samples, although two-thirds of the isolates came from just one plant (A). Geobacillus has frequently been reported as a common thermophilic spore contaminant of dairy powders (Rückert et al., 2004; Scott et al., 2007; Yuan et al., 2012); however, it was not widespread in this this study. Interestingly, Geobacillus was isolated from raw milk and cheese whey from 3 dairy powder processing facilities in this study (plants A, G, and $\mathrm{H}$ ), and cheese whey yielded half of the Geobacillus isolates $(\mathrm{n}=10)$ from plant A, the only facility manufacturing WPC in this study. Only one previous study has described the presence of Geobacillus in raw milk (Miller et al., 2015b); however, relatively few studies have both enumerated thermophilic spores in raw milk and subsequently identified those microorganisms (e.g., Coorevits et al., 2008), which likely accounts for the lack of data describing Geobacillus in raw milk. It must also be noted that the raw milk (and other raw material) samples from this study were obtained from raw milk storage tanks at the processing facility. It cannot be ruled out, therefore, that the raw materials were contaminated in the processing facility or even during transport from the farm to the processing facility. More work is needed to determine the prevalence of raw milk 
contamination with Geobacillus and potential farm factors that may lead to transmission of this organism into the dairy powder continuum.

Surprisingly, Anoxybacillus, which represented one of the most commonly isolated thermophilic sporeformers in previous studies (Rückert et al., 2004; Scott et al., 2007; Reginensi et al., 2011; Yuan et al., 2012) was isolated only once in this study. Anoxybacillus has been shown to form biofilms in dairy powder processing facilities, thereby contaminating the product in increasing amounts throughout a processing run. Scott et al. (2007) found that thermophilic spore counts in powder, primarily consisting of Anoxybacillus and Geobacillus, increased by nearly 4 orders of magnitude from the beginning of a processing run through the end $(\sim 18$ h) in one plant, due primarily to spores present in foulant sloughed off during production. Several studies have shown that Anoxybacillus is capable of producing biofilms in dairy processing equipment (Flint et al., 1997; Scott et al., 2007). Anoxybacillus, therefore, may be specific to individual processing facilities where it has managed to create biofilms. This idea is supported by the results of the current study indicating that populations of sporeforming bacteria differ significantly between processing plants. Additionally, the lack of significant increase in spore counts throughout processing found in this and previous work (Watterson et al., 2014) may be due to the absence of biofilms containing the sporeformers previously associated with postprocessing contamination (i.e., Anoxybacillus) in the powder facilities surveyed here.

\section{Distinguishing Between Sources of Spores Requires Improved Discriminatory Tests}

In this study, rpoB allelic typing was used as a subtyping method for sporeforming bacteria. This method was developed for differentiating between closely related sporeforming bacteria in dairy products and environments (Durak et al., 2006). This method has previously been used for characterization and identification of sporeformers in raw milk (Huck et al., 2007a,b, 2008; Ivy et al., 2012; Masiello et al., 2014), fluid milk (Huck et al., 2007a,b; Ivy et al., 2012), dairy powders (Miller et al., 2015b), and the dairy farm environment (Huck et al., 2008, Ivy et al., 2012). Although this method offers improved subtype discrimination over $16 \mathrm{~S}$ rDNA sequencing (Durak et al., 2006), phenotypic differences including enzyme production and optimal growth temperature have been described between members of the same rpoB AT (Ivy et al., 2012; Trmčić et al., 2015), including Bacillus licheniformis rpoB AT1, which accounted for approximately $30 \%$ of the isolates recovered in this study. This phenotypic variability suggests that the $r p o B$ allelic typing system has limited discriminatory power within this important dairy-associated strain.

Because aerobic sporeformers can both originate from raw milk and survive processing (Watterson et al., 2014; Miller et al., 2015b) and originate from the processing facility (Flint et al., 1997; Scott et al., 2007; Burgess et al., 2010), source-tracking is an invaluable tool to inform the development and implementation of intervention strategies. Other methods of subtyping have been used for Bacillus isolates drawn from dairy sources, including rapid amplification of polymorphic DNA (RAPD)-PCR, BOX-A1R-based repetitive extragenic palindromic PCR (BOX-PCR), repetitive element sequence-based (REP)-and REP-I-PCR, and (GTG) PCR fingerprinting (Ronimus et al., 2003; Rückert et al., 2003; De Jonghe et al., 2008; Banykó and Vyletelova, 2009; Reginensi et al., 2011), ribotyping (Andersson et al., 1999), high-resolution melt analysis (Chauhan et al., 2013; Dhakal et al., 2013), multilocus sequence typing (Helgason et al., 2004; Ko et al., 2004), Fourier transform infrared spectroscopy (Beattie et al., 1998), and multiparametric real-time PCR (Postollec et al., 2010, 2012). More work is needed to understand how the discriminatory power of these methods compares with the rpo $B$ allelic typing used in this study, and whether the use of such subtyping methods is viable as a source-tracking tool in industry.

\section{CONCLUSIONS}

This study highlights the need to apply a standardized set of methods for enumeration of groups of aerobic spores in dairy products. The current lack of standardization in testing methods has made benchmarking spore counts in dairy powders from different plants and even countries an impossibility. Our results indicate that a single spore test is not sufficient for determining the true concentration of spores in a dairy powder due to the changes in spore populations caused by various testing parameters. This point was further supported by the low correlations seen between the spore counts from various testing methods. Further, there needs to be a focus on Bacillus licheniformis as a major dairy continuum contaminant and major contributor to dairy powder spore counts. Reducing spore counts in dairy powders will require a better understanding of contamination sources and transmission patterns for this sporeformer.

\section{ACKNOWLEDGMENTS}

The funding for this project was provided by the Dairy Research Institute (Rosemont, IL). The authors thank the members of the Milk Quality Improvement 
Program (Cornell University) for their contributions to this work. We also thank the dairy powder processing facilities that voluntarily participated in this study.

\section{REFERENCES}

Andersson, A., B. Svensson, A. Christiansson, and U. Ronner. 1999. Comparison between automatic ribotyping and random amplified polymorphic DNA analysis of Bacillus cereus isolates from the dairy industry. Int. J. Food Microbiol. 47:147-151.

Banykó, J., and M. Vyletelova. 2009. Determining the source of $B a-$ cillus cereus and Bacillus licheniformis isolated from raw milk, pasteurized milk and yoghurt. Lett. Appl. Microbiol. 48:318-323.

Beattie, S. H., C. Holt, D. Hirst, and A. G. Williams. 1998. Discrimination among Bacillus cereus, B. mycoides and B. thuringiensis and some other species of the genus Bacillus by Fourier transform infrared spectroscopy. FEMS Microbiol. Lett. 164:201-206.

Buehner, K. P., S. Anand, and A. Garcia. 2014. Prevalence of thermoduric bacteria and spores on 10 midwest dairy farms. J. Dairy Sci. 97:6777-6784.

Burgess, S. A., D. Lindsay, and S. H. Flint. 2010. Thermophilic bacill and their importance in dairy processing. Int. J. Food Microbiol. $144: 215-225$

Carlin, F. 2011. Origin of bacterial spores contaminating foods. Food Microbiol. 28:177-182

Chauhan, K., R. Dhakal, R. B. Seale, H. C. Deeth, C. J. Pillidge, I. B Powell, H. Craven, and M. S. Turner. 2013. Rapid identification of dairy mesophilic and thermophilic sporeforming bacteria using DNA high resolution melt analysis of variable $16 \mathrm{~S}$ rDNA regions. Int. J. Food Microbiol. 165:175-183.

Cole, J. R., Q. Wang, J. A. Fish, B. Chai, D. M. McGarrell, Y. Sun, C. T. Brown, A. Porras-Alfaro, C. R. Kuske, and J. M. Tiedje. 2014 Ribosomal Database Project: Data and tools for high throughput rRNA analysis. Nucleic Acids Res. 42:D633-D642.

Coorevits, A., V. De Jonghe, J. Vandroemme, R. Reekmans, J. Heyrman, W. Messens, P. De Vos, and M. Heyndrickx. 2008. Comparative analysis of the diversity of aerobic spore-forming bacteria in raw milk from organic and conventional dairy farms. Syst. Appl. Microbiol. 31:126-140.

Crielly, E. M., N. A. Logan, and A. Anderton. 1994. Studies on the Bacillus flora of milk and milk products. J. Appl. Bacteriol. $77: 256-263$.

De Jonghe, V., A. Coorevits, J. Vandroemme, J. Heyrman, L. Herman, P. De Vos, and M. Heyndrickx. 2008. Intraspecific genotypic diversity of Bacillus species from raw milk. Int. Dairy J. 18:496-505.

Dhakal, R., K. Chauhan, R. B. Seale, H. C. Deeth, C.J. Pillidge, I. B Powell, H. Craven, and M.S. Turner. 2013. Genotyping of dairy Bacillus licheniformis isolates by high-resolution melt analysis of multiple variable number tandem repeat loci. Food Microbiol. 34:344-351.

Dugan, K. A., H. S. Lawrence, D. R. Hares, C. L. Fisher, and B. Budowle. 2002. An improved method for post-PCR purification for mtDNA sequence analysis. J. Forensic Sci. 47:811-818.

Durak, M. Z., H. I. Fromm, J. R. Huck, R. N. Zadoks, and K. J. Boor. 2006. Development of molecular typing methods for Bacillus spp. and Paenibacillus spp. isolated from fluid milk products. J. Food Sci. 71:M50-M56.

Edgar, R. C. 2004. MUSCLE: Multiple sequence alignment with high accuracy and high throughput. Nucleic Acids Res. 32:1792-1797.

Flint, S. H., P. J. Bremer, and J. D. Brooks. 1997. Biofilms in dairy manufacturing plant-Description, current concerns and methods of control. Biofouling 11:81-97.

Frank, J. F., and A. E. Yousef. 2004. Tests for groups of microorganisms. Pages 227-248 in Standard Methods for the Examination of Dairy Products. 17th ed. H. M. Wehr and J. F. Frank, ed. Am. Public Health Assoc., Washington, DC.

Helgason, E., N. J. Tourasse, R. Meisal, D. A. Caugant, and A. B. Kolsto. 2004. Multilocus sequence typing scheme for bacteria of the Bacillus cereus group. Appl. Environ. Microbiol. 70:191-201.
Hill, B. M. 2004. Thermophilic spores: UHT and retort processing of recombined milks. Pages 184-193 in Proc. 4th Int. Symp. Recombined Milk and Milk Products. US Dairy Export Council, Cancun, Mexico.

Huck, J. R., B. H. Hammond, S. C. Murphy, N. H. Woodcock, and K. J. Boor. 2007b. Tracking spore-forming bacterial contaminants in fluid milk-processing systems. J. Dairy Sci. 90:4872-4883.

Huck, J. R., M. Sonnen, and K. J. Boor. 2008. Tracking heat-resistant, cold-thriving fluid milk spoilage bacteria from farm to packaged product. J. Dairy Sci. 91:1218-1228.

Huck, J. R., N. H. Woodcock, R. D. Ralyea, and K. J. Boor. 2007a. Molecular subtyping and characterization of psychrotolerant endospore-forming bacteria in two New York State fluid milk processing systems. J. Food Prot. 70:2354-2364.

ISO-IDF. 2009. Dried milk: Enumeration of the specially thermoresistant spores of thermophilic bacteria. International Organization for Standardization (ISO), Geneva, Switzerland, and International Dairy Federation (IDF), Brussels, Belgium.

Ivy, R. A., M. L. Ranieri, N. H. Martin, H. C. den Bakker, B. M. Xavier, M. Wiedmann, and K. J. Boor. 2012. Identification and characterization of psychrotolerant sporeformers associated with fluid milk production and processing. Appl. Environ. Microbiol. 78:1853-1864.

Ko, K. S., J. W. Kim, J. M. Kim, W. Kim, S. I. Chung, I. J. Kim, and Y. H. Kook. 2004. Population structure of the Bacillus cereus group as determined by sequence analysis of six housekeeping genes and the plcR gene. Infect. Immun. 72:5253-5261.

Larsson, A. 2014. AliView: a fast and lightweight alignment viewer and editor for large datasets. Bioinformatics 30:3276-3278.

Logan, N. A., and P. De Vos. 2009. Genus I. Bacillus. Pages 21-128 in Bergey's Manual of Systematic Bacteriology, Vol. 3. P. De Vos, G. M. Garrity, D. Jones, N. R. Krieg, W. Ludwig, F. A. Rainey, K. Schleifer and W. B. Whitman, ed. Springer, New York, NY.

Logan, N. A., P. De Vos, and A. Dinsdale. 2009. Genus VII. Geobacillus. Pages 144-160 in Bergey's Manual of Systematic Bacteriology, Vol. 3. P. De Vos, G. M. Garrity, D. Jones, N. R. Krieg, W. Ludwig, F. A. Rainey, K. Schleifer and W. B. Whitman, ed. Springer, New York, NY.

Masiello, S. N., N. H. Martin, R. D. Watters, D. M. Galton, Y. H. Schukken, M. Wiedmann, and K. J. Boor. 2014. Identification of dairy farm management practices associated with the presence of psychrotolerant sporeformers in bulk tank raw milk. J. Dairy Sci. 97:4083-4096.

Miller, R. A., D. J. Kent, K. J. Boor, N. H. Martin, and M. Wiedmann. 2015a. Different management practices are associated with mesophilic and thermophilic spore levels in bulk tank raw milk. J. Dairy Sci. 98:4338-4351.

Miller, R. A., D. J. Kent, M. J. Watterson, K. J. Boor, N. H. Martin, and M. Wiedmann. 2015b. Spore populations among bulk tank raw milk and dairy powders are significantly different. J. Dairy Sci. 98:8492-8504.

Muir, D. D., M. W. Griffiths, J. D. Phillips, A. W. M. Sweetsur, and I. G. West. 1986. Effect of the bacterial quality of raw milk on the bacterial quality and some other properties of low-heat and highheat dried milk. Int. J. Dairy Technol. 39:115-118.

Murphy, P. M., D. Lynch, and P. M. Kelly. 1999. Growth of thermophilic spore forming bacilli in milk during the manufacture of low heat powders. Int. J. Dairy Technol. 52:45-50.

Pikuta, E. V. 2009. Genus IV. Anoxybacillus. Pages 134-141 in Bergey's Manual of Systematic Bacteriology, Vol. 3. P. De Vos, G M. Garrity, D. Jones, N. R. Krieg, W. Ludwig, F. A. Rainey, K. Schleifer, and W. B. Whitman, ed. Springer, New York, NY.

Postollec, F., S. Bonilla, F. Baron, S. Jan, M. Gautier, A. G. Mathot, S. Hallier-Soulier, S. Pavan, and D. Sohier. 2010. A multiparametric PCR-based tool for fast detection and identification of sporeforming bacteria in food. Int. J. Food Microbiol. 142:78-88.

Postollec, F., A. G. Mathot, M. Bernard, M. L. Divanac'h, S. Pavan, and D. Danièle. 2012. Tracking spore-forming bacteria in food: From natural biodiversity to selection by processes. Int. J. Food Microbiol. 158:1-8. 
Ralyea, R. D., M. Wiedmann, and K. J. Boor. 1998. Bacterial tracking in a dairy production system using phenotypic and ribotyping methods. J. Food Prot. 61:1336-1340.

Ranieri, M. L., and K. J. Boor. 2009. Short communication: Bacterial ecology of high-temperature, short-time pasteurized milk processed in the United States. J. Dairy Sci. 92:4833-4840.

R Core Team. 2015. R: A language and environment for statistical computing. R Foundation for Statistical Computing, Vienna, Austria. https://www.R-project.org/.

Reginensi, S. M., M. J. Gonzalez, J. A. Olivera, M. Sosa, P. Juliano, and J. Bermudez. 2011. RAPD-based screening for spore-forming bacterial populations in Uruguayan commercial powdered milk. Int. J. Food Microbiol. 148:36-41.

Ronimus, R. S., L. E. Parker, N. Turner, S. Poudel, A. Ruckert, and H. W. Morgan. 2003. A RAPD-based comparison of thermophilic bacilli from milk powders. Int. J. Food Microbiol. 85:45-61.

Rückert, A., R. S. Ronimus, and H. W. Morgan. 2004. A RAPD-based survey of thermophilic bacilli in milk powders from different countries. Int. J. Food Microbiol. 96:263-272.

Scheldeman, P., A. Pil, L. Herman, P. De Vos, and M. Heyndrickx. 2005. Incidence and diversity of potentially highly heat-resistant spores isolated at dairy farms. Appl. Environ. Microbiol. 71:14801494.

Scott, S. A., J. D. Brooks, J. Rakonjac, K. M. R. Walker, and S. H. Flint. 2007. The formation of thermophilic spores during the manufacture of whole milk powder. Int. J. Dairy Technol. 60:109-117.
Stamatakis, A. 2006. RAxML-VI-HPC: Maximum likelihood-based phylogenetic analyses with thousands of taxa and mixed models. Bioinformatics 22:2688-2690.

te Giffel, M. C., A. Wagendorp, A. Herrewegh, and F. Driehuis. 2002. Bacterial spores in silage and raw milk. Antonie Van Leeuwenhoek $81: 625-630$.

Trmčić, A., N. H. Martin, K. J. Boor, and M. Wiedmann. 2015. A standard bacterial isolate set for research on contemporary dairy spoilage. J. Dairy Sci. 98:5806-5817.

Vissers, M. M. M., F. Driehuis, M. C. Te Giffel, P. De Jong, and J. M. G. Lankveld. 2006. Improving farm management by modeling the contamination of farm tank milk with butyric acid bacteria. J. Dairy Sci. 89:850-858.

Watterson, M. J., D. J. Kent, K. J. Boor, M. Wiedmann, and N. H. Martin. 2014. Evaluation of dairy powder products implicates thermophilic sporeformers as the primary organisms of interest. J. Dairy Sci. 97:2487-2497.

Yuan, D. D., G. C. Liu, D. Y. Ren, D. Zhang, L. Zhao, C. P. Kan, Y. Z. Yang, W. Ma, Y. Li, and L. B. Zhang. 2012. A survey on occurrence of thermophilic bacilli in commercial milk powders in China. Food Contr. 25:752-757. 